\title{
(DES)MEMÓRIAS: por uma revisão feminista da História da Arte no Brasil
}

\author{
ANa MaE BARBOSA \\ UNIVERSIDADE DE SÃO PAULO - USP
}

\section{Resumo}

As mulheres artistas foram apagadas da História da Arte do século XIX no Brasil e só a partir da Semana de Arte Moderna de 1922, que introduziu os brasileiros aos códigos modernistas é que mulheres passaram a ter visibilidade na Arte do Brasil.

Mesmo na mega exposição que teve lugar no ano 2000, "comemorativa" dos 500 anos da colonização do Brasil pelos portugueses, as mulheres foram banidas. No segmento sobre o século XIX não havia nenhuma mulher entre os quase duzentos artistas apresentados apesar de que muitas foram bem sucedidas em vida, ganhando prêmios até na Europa.

A grande produção das mulheres nas artes visuais hoje no Brasil tem paulatinamente incorporado as conquistas feministas, mas o medo de ser considerada feminista ainda ronda mulheres artistas, historiadoras, críticas e arte/educadoras.

O mal da desmemoria mais agudo e amplo não se dá apenas na mente dos velhos como eu, nem mesmo dos infelizmente acometidos pelo mal de Alzheimer ou pelo mal de Parkinson, até porque estes males estão sendo minorados pela medicina.

A mal da desmemoria mais avassalador é o que atinge a história das mulheres em todas as áreas do conhecimento. Para este mal a obrigação de pesquisar é nossa, de nós mulheres, que devemos buscar também convencer os homens a participar de nossas pesquisas restauradoras da memória da participação das mulheres, no meu caso, nas áreas de Artes Visuais e de Arte/Educação.

Em 2019 publiquei com a colaboração de Vitória Amaral uma pesquisa sobre mulheres Arte/Educadoras da década de sessenta que foram influentes na área do ensino da Arte no Brasil e até mesmo na política para as Artes. Trata-se do 
livro "Mulheres não devem ficar em silencio: Arte, Design e Educação" ${ }^{43}$ que teve a participação de seis pesquisadores homens e seis pesquisadoras.

Mas não esgotei o tema, nem sequer em relação ao tempo delimitado para a pesquisa. Embora o livro tenha 420 páginas muitas arte/educadoras importantes dos anos 60 tiveram de ser deixadas de fora para que o livro tivesse apenas um volume. Contudo a desmemoria atinge não só as mulheres Arte/Educadoras, uma área considerada periférica, mas as artistas mulheres no Brasil e no mundo em geral. Muitas delas foram importantes em seu tempo mas enquanto seus colegas homens permaneceram famosos elas foram sendo marginalizadas pela história.

Provavelmente todos que lerem este artigo conhecem a instalação/pesquisa, O Dinner Party de Judy Chicago considerada o marco inicial do movimento feminista. Chicago operou um raciocínio social básico. Os homens tiveram a Santa Ceia que mudou o mundo, as mulheres só têm jantares de festas. Onde ficou a contribuição das mulheres nas ciências, na teologia, na história, nas Artes, na construção do conhecimento que resultou no mundo do século XX?

Chicago trabalhou com mais de 400 mulheres começando pela pesquisa da contribuição das mulheres em todos os campos do saber. Depois de seis anos de trabalho apresentou sua instalação, uma mesa triangular em um chão de azulejos com a impressão dos nomes de todas as mulheres estudadas. A mesa era composta de 13 lugares de cada lado, ao todo 39 lugares, representando cada lugar a mulher mais importante de sua área. Cada lugar tinha um jogo americano bordado, um prato de cerâmica redondo com decoração em forma de vaginas e um copo. Só os copos eram todos iguais e projetados por um designer homem. Cerâmica e bordado eram atividades consideradas de segunda categoria, artesanato, "coisa de mulher", e não Arte. Sua intenção era questionar este preconceito. Sua maior dificuldade foi o fato de que não havia sequer uma escola para as suas colaboradoras aprenderem a bordar, o único lugar que encontrou foi um atelier de bordados para paramentos de padres. Sem Judy Chicago não teríamos Leonilson nem Rosana Palazian. Tive a sorte de ver a primeira exposição do Dinner Party no Museu de Arte Contemporânea de São Francisco em 1979.

Era tão forte aquela instalação que os visitantes espontaneamente faziam uma fila interminável e andavam silenciosa e atentamente ao redor da mesa como se fora um ritual. A sociedade americana e os críticos atacaram veementemente o trabalho de Chicago, uns porque o consideravam imoral, outros porque o consideravam "kitsch" frente ao modernismo "clean" do MOMA que até hoje é cultivado pelos Museus no Brasil.

43 BARBOSA, Ana Mae; AMARAL, Vitoria (Orgs.). Mulheres não devem ficar em silencio: Arte, Design e Educação. São Paulo, Editora Cortez: 2019. 


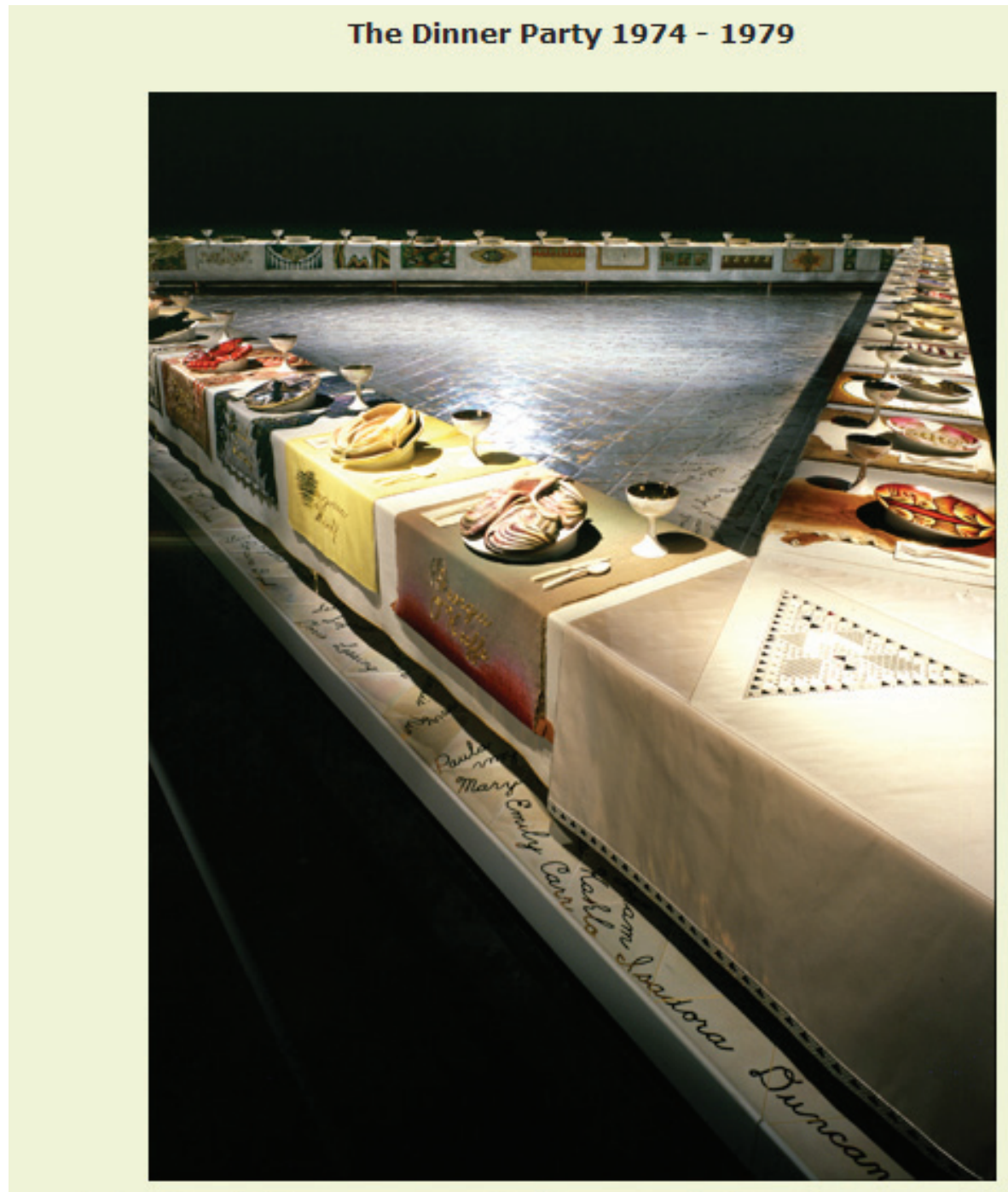

Installation view of The Dinner Party looking across the first Millennium Runner and down wings one and three.

(c) Judy Chicago - Photo \& Donald Woodman 


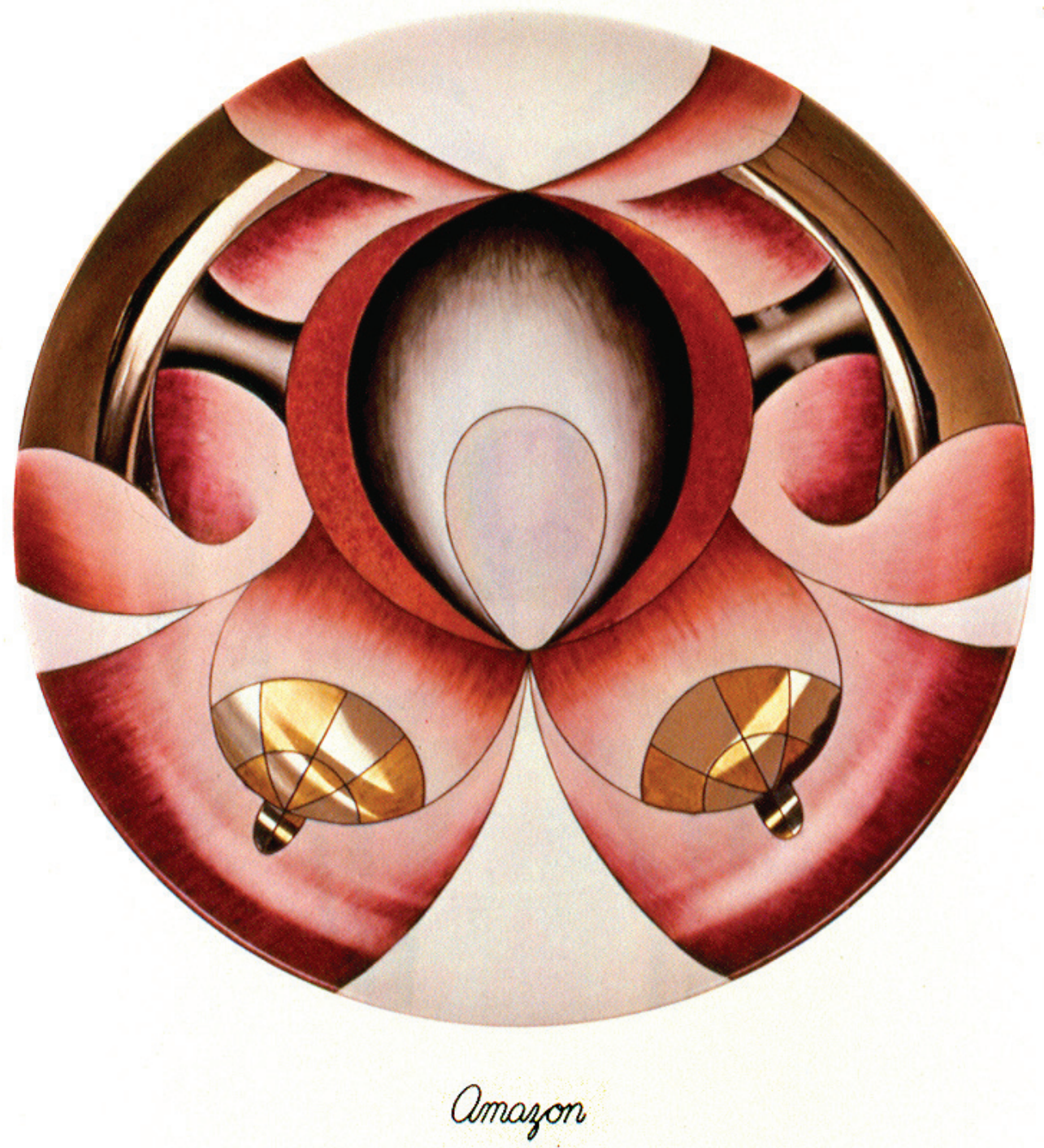

Fonte: livro The Dinner Party de Judy Chicago 1995

Depois da exposição viajar por vários países teve dificuldade em encontrar abrigo permanente em museus nos USA pois os políticos e os ricos que dominam o Conselho dos Museus a consideravam pornográfica. Finalmente depois de 10 anos em um depósito se degradando está permanentemente exposta no Museu do Brooklin em New York. 
Apesar do fato de haver um grande número de artistas mulheres no Brasil, o 'homem' ainda é o valor canônico universal. As mulheres só conseguem valorização justa se aceitam o masculino como norma. A igualdade no Brasil não leva em conta a diferença. O discurso de igualdade e o discurso da diferença, entretanto, precisam ser articulados em conjunto para possibilitar à mulher ser o sujeito de seu próprio discurso.

As artistas mulheres do Século XIX e inícios do Século XX foram apagadas da História da Arte. Tiveram sucesso no seu tempo, ganharam medalhas e até prêmios de viagens mas hoje são desconhecidas. Em minhas pesquisas, somente em Recife e Belo Horizonte (anos 90), encontrei estudantes que conheciam Fédora do Rego Monteiro, por ter sido irmã de Vicente do Rego Monteiro e Zina Aita de Belo Horizonte, por ter participado da Semana de Arte Moderna. Ainda assim, mesmo em uma tese sobre artistas mulheres defendida em 1994 na UFRJ, a mineira Zina Aita é identificada como paulista (Regina Célia Pinto, 1994). No século XXI já foram publicados três livros muito importantes reescrevendo a história de mulheres artistas no Brasil, são eles o de Ana Paula Simioni, Profissão Artista (2004), o de Roberta Barros Elogio ao toque: ou como falar de arte feminista à brasileira. (2016) e o de Madalena Zaccara, De sinhá prendada a artista visual: os caminhos da mulher artista em Pernambuco (2017).

Ignorância sobre a Arte das mulheres como reclamam Griselda Pollock, desde muito tempo, e mais recentemente Frances Spalding não significa apenas esquecimento de seus nomes, destruição de suas obras pelo descaso mas principalmente "invisibilidade de significação" 4 .

Algumas, muito poucas, devem a colecionadores iluminados sua sobrevivência histórica, embora de conhecimento restrito a círculos muito especializados. É o caso de Sarah Villela, cuja obra quase toda estava nas mãos diligentes de Agenor Rodrigues Valle, uma das figuras do mundo das Artes mais interessantes que já conheci, de simpatia, generosidade, desprendimento e respeito pelo mundo feminino fora do comum. Depois de sua morte, não sei onde estão. Mas quem tem informações sobre Carlota do Nascimento, única aluna negra da Escola Nacional de Belas Artes do Rio de Janeiro nos inícios do século XX, amiga de Sarah Vilela ${ }^{45}$ ?

Entrevistei Agenor Rodrigues sobre meu interesse em estudar Georgina de Albuquerque, Silvia Meyer e Maria Pardos. Foi uma conversa deliciosa. Ele ficou de pesquisar e me enviar o que encontrasse sobre as três. Dias depois ele me

44 SPALDING, Frances. Garden Ceremony. In: TLS,19 de Fevereiro de 1999, pg. 19

45 Informação de Agenor Rodrigues Valle e Miriam Andrea de Oliveira em entrevista no Rio de Janeiro, 4 de junho de 1999. 
enviou pelo correio este texto, que não sei se é escrito por ele que infelizmente já faleceu. Não tinha referência bibliográfica:

\begin{abstract}
"A abertura dos Salões anuais, na Academia, era uma grande festa, com a presença do Imperador, dos professores, alunos, críticos de arte e convidados. Depois de um longo discurso do diretor, passava-se à entrega dos prêmios, seguindo os critérios bastante conservadores da comissão julgadora, com registro em ata.

Poisénaleitura dessasatasquevamosencontrarapresençafeminina se insinuando, a partir dos anos 70. Em 1876, Francisca Breves ganhaa $2^{\text {a }}$ Medalha de Ouroe Elvira Airosa fica com Menção Honrosa. A partir de 1894, a presença de mulheres nas premiações passa a ser uma constante, quase sempre com simples menção honrosa de $1^{\circ}$ e $2^{\circ}$ graus.

Existem, porém, exceções. Em 1900, por exemplo, Julieta França ganha o cobiçado prêmio de viagem ao exterior e torna-se pensionista da República. Em 1905, Ana Vasco e Maria Vasco, alunas de Benno Treidel e participantes de seguidas exposições, ganham a medalha de prata. O mesmo acontece com Georgina de Albuquerque em 1912 e 1916. Maria Pardos e Sílvia Meyer também conquistam esse prêmio em 1915”.
\end{abstract}

Nossa tarefa é árdua e muito ampla. Precisamos, como em outras áreas da História, de pesquisas e publicações que visem reinscrever as mulheres na sociedade que ajudaram a construir no passado, mas além disso é necessário por serem artistas ressignificá-las enquanto produtoras de imagens colocando à disposição do público de hoje suas obras organizadas em exposições significativas, tanto pela quantidade quanto pela qualidade da escolha e da narrativa curatorial.

Para recuperar a visibilidade das mulheres em Arte, precisamos não só do discurso verbal analítico de suas obras mas principalmente do discurso visual oferecido pelas exposições.

Nem mesmo Georgina de Albuquerque é conhecida pelo público que frequenta palestras sobre Arte ou por todos os estudantes de Arte. Foi a primeira mulher a dirigir a Escola Nacional de Belas Artes, fez concurso bem sucedido para Catedrática em 1942. Este cargo era muito importante na época, dava muito mais poder que têm os professores titulares de hoje; era sufragista, isto é, defendia o direito de voto para as mulheres de todas as classes sociais. Georgina Albuquerque tinha muito prestígio no seu tempo e somava ao seu próprio prestígio o prestígio do marido Lucilio de Albuquerque (1887-1939) a quem dedica a tese escrita depois da morte dele. Ser casada, amante ou filha de homem importante sempre foi uma faca de dois gumes para as mulheres, pois possibilita que os antifeminis- 
tas as respeitem hipocritamente em público no momento de sua ascensão mas as desqualifiquem em privado e ao longo do tempo dizendo que só são consideradas por terem associação com um homem importante. Não sei se por esta razão ou se foi simplesmente o machismo determinante da história, mas Georgina ficou esquecida por quase meio século.

Me enche de alegria ver que o movimento feminista vem recuperando sua trajetória e sua presença em exposições, o que é muito relevante por ter sido ela própria uma feminista da primeira onda. Mulheres de hoje, ao se aliarem ao feminismo vocês estão lutando contra o apagamento de mulheres pela História e contra o seu próprio apagamento.

Uma exposição em Santiago do Chile intitulada "Yo soy mi propia musa. Pintoras latinoamericanas de entreguerras (1919-1939)", 17 de abril a 30 de junho de 2019 no Museo Nacional de Bellas Artes inclui obra de Georgina de Albuquerque junto as brasileiras Tarsila do Amaral (1886-1979), Lucy Citti Ferreira (1911-2008), Noemia Mourão (1912-1992) y Anita Malfatti (1889-1964).

Destas mulheres artistas brasileiras Anita e Tarsila ${ }^{46}$ são muito comemoradas hoje mas estiveram no ostracismo na década de 40 de onde foram resgatadas por mulheres pesquisadoras da Arte, respectivamente Aracy Amaral e Marta Rossetti que escreveram sobre elas. Este é um exemplo claro de que mulheres precisam escrever sobre mulheres se queremos reescrever a História da Arte sob uma perspectiva democrática, igualitária. Lucy Citti Ferreira foi simbolicamente enterrada aos pés do comemorado Lasar Segall sendo considerada apenas sua modelo e musa pela crítica.

Sempre houve muita dificuldade em enquadrar a produção das mulheres nos ismos historicamente determinados. Frida Kahlo e Grete Stern foram consideradas surrealistas e Georgina impressionista, quando foram apenas mulheres que tinham consciência de serem mulheres e artistas. Georgina tinha orgulho de ter trabalhado todos os dias de sua vida, até mesmo quando os filhos Dante e Flamingo eram pequenos. Foi a primeira mulher a fazer uma pintura histórica. Até hoje este gênero é negado às mulheres. Um exemplo da proibição disfarçada é a consideração tardia pela magnifica pintura de Teresa Costa Rego representando a Guerra dos Guararapes (uma exposição que faz jus a obra histórica desta artista só foi feita em seus 90 anos). A obra histórica de Georgina intitulada Sessão do Conselho de Estado de 1922 comemora a Independência e pertence ao Museu Histórico Nacional do Rio de Janeiro. Esta obra foi analisada negativamente por

46 A exposição de Tarsila Popular no MASP que se encerrou dia 28 de julho de 2019 foi visitada por 402.000 visitantes, o maior número de visitantes de uma exposição no Brasil. 
um crítico de Arte homem. .Monteiro Lobato não foi o único crítico homem a desqualificar uma artista mulher como veremos mais abaixo neste texto no caso de Malfatti. Era quase um clichê crítico naquela época os homens procurarem baixar a autoestima das mulheres, "baixar a bola" como se diz hoje.

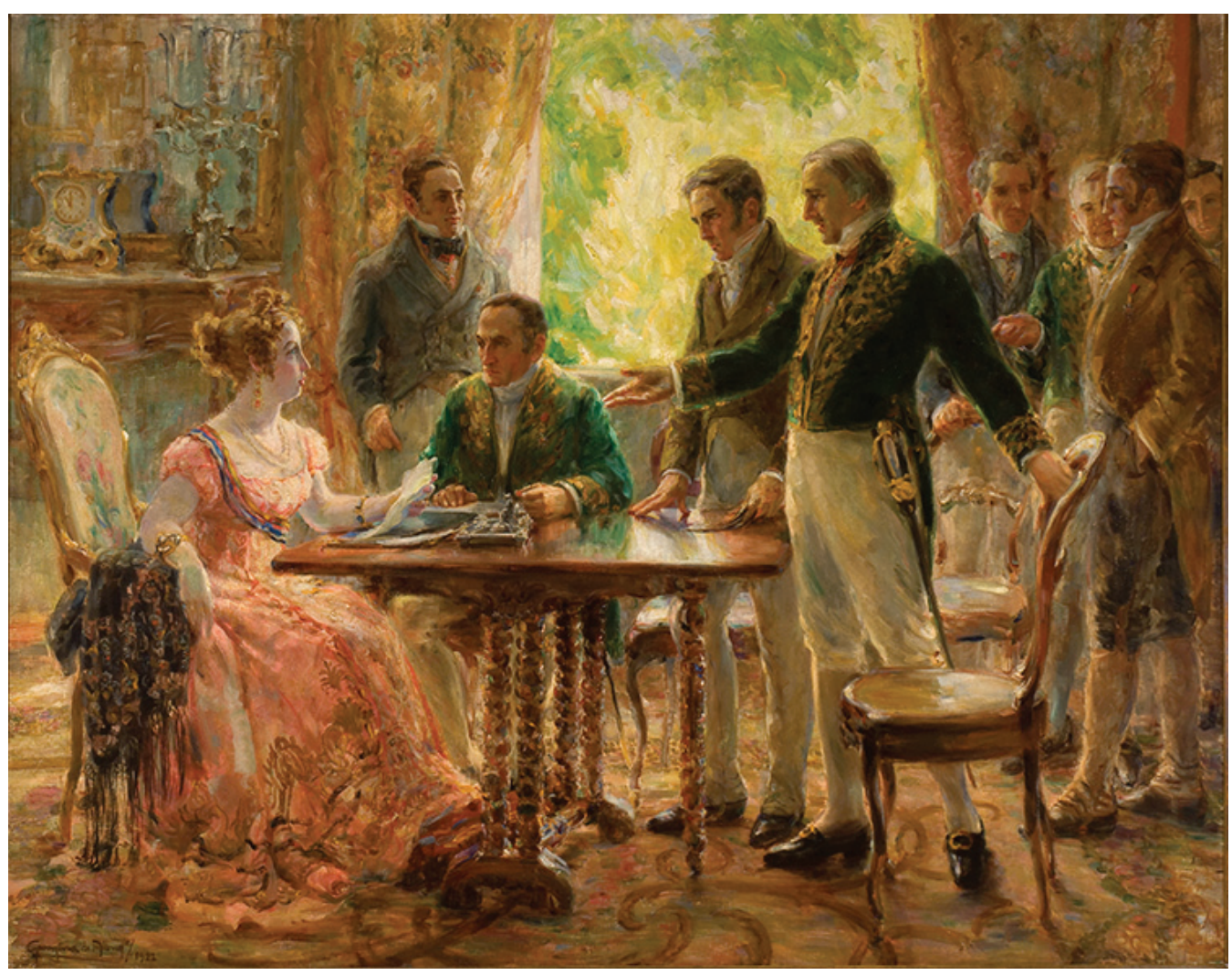

Figura: Sessão do Conselho de Estado, Georgina de Albuquerque.

Fonte: https://ww.museudeartedorio.org.br/en/node/3969, consultado dia 31/07/2019

O site do MAR onde esta obra esteve recentemente exposta comenta:

"Na obra Sessão do Conselho de Estado, Georgina de Albuquerque apresentará em 1922 a primeira pintura de gênero histórico, uma obra em grandes dimensões feita por uma artista brasileira. Trata-se também da primeira tela que confere à Imperatriz Leopoldina seu papel ativo como estadista no exato momento em que assume posição favorável à Independência do Brasil junto a José Bonifácio, Clemente Pereira, Martim Francisco, Gonçalves 
Ledo e outros civis- alguns dos quais vestem a farda verde usada após a Independência pela alta patente do exército imperial brasileiro sugerindo o triunfo da escolha política decorrente do momento encenado.

A obra com características impressionistas e temática própria do formalismo academicista em voga foi realizada para participar do concurso da Exposição do Centenário da Independência que previa a realização de uma mostra sobre as principais modalidades de trabalho. Para o evento foram produzidas duas pinturas que realçaram a participação da Imperatriz Leopoldina na história nacional: a de Georgina de Albuquerque que encontra-se hoje em exposição permanente no Museu Histórico Nacional e a tela de Domenico Failutti Retrato de Dona Leopoldina de Habsburgo e seus filhos (1921), exibida no núcleo Dona Leopoldina e sua descendência desta exposição. ${ }^{47}$

Como feminista, Georgina nesta obra não só afirma a participação política da Imperatriz Leopoldina na Independência do Brasil como destaca sua participação no gesto em direção a ela de José Bonifácio, homem a quem se atribuiu sozinho por algum tempo a redação da primeira Constituição brasileira. Hoje sabe-se que ela muito contribuiu para a escrita da Constituição e para o reconhecimento da Independência do Brasil pelas potencias estrangeiras. É verdade que teve de pagar a aprovação da nossa Independência a seu país de origem, a Áustria, criando assim mais uma dívida externa para o Brasil além da que já "tínhamos" com Portugal. Se a História oficial destaca José Bonifácio que tem um monumento em praça pública com sua figura austera em New York atrás da Biblioteca Pública na Quinta Avenida entre as ruas 42 e 43, Leopoldina tem a maior homenagem que o povo brasileiro pode prestar a alguém, é referenciada pela Escola de Samba a famosa Imperatriz Leopoldinense criada em 1959. O nome da Escola é em homenagem a Estrada de Ferro Leopoldina, que foi assim designada em homenagem direta à Imperatriz Leopoldina. A estrada de Ferro Leopoldina atravessava o bairro de Ramos onde está baseada hoje a Escola de Samba. Logo seu título é homenagem indireta à Imperatriz. Sem querer, por acaso, se fez justiça histórica, pois a maior homenagem que alguém pode ter no Brasil é o nome numa Escola de Samba ou ser tema de um desfile.

\footnotetext{
47 https://www.museudeartedorio.org.br/en/node/3969, consultado dia 31/07/2019.
} 


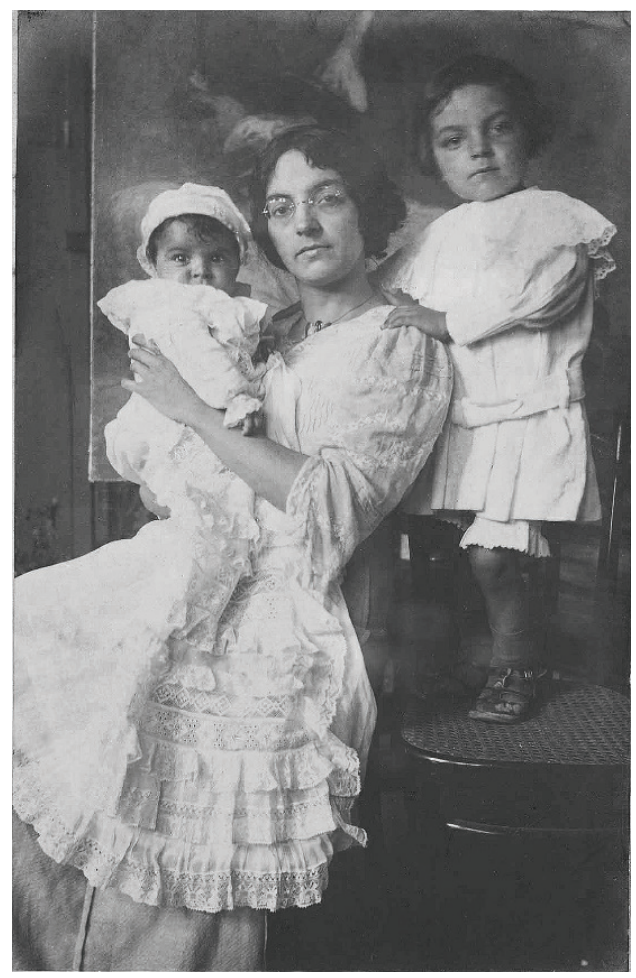

D. Georgina de Albuquerque, pintora, Fotografia de M. Nogueira da Silva, 191-?.

Disponível em:

http://acervo.bndigital.bn.br/sophia/index. html

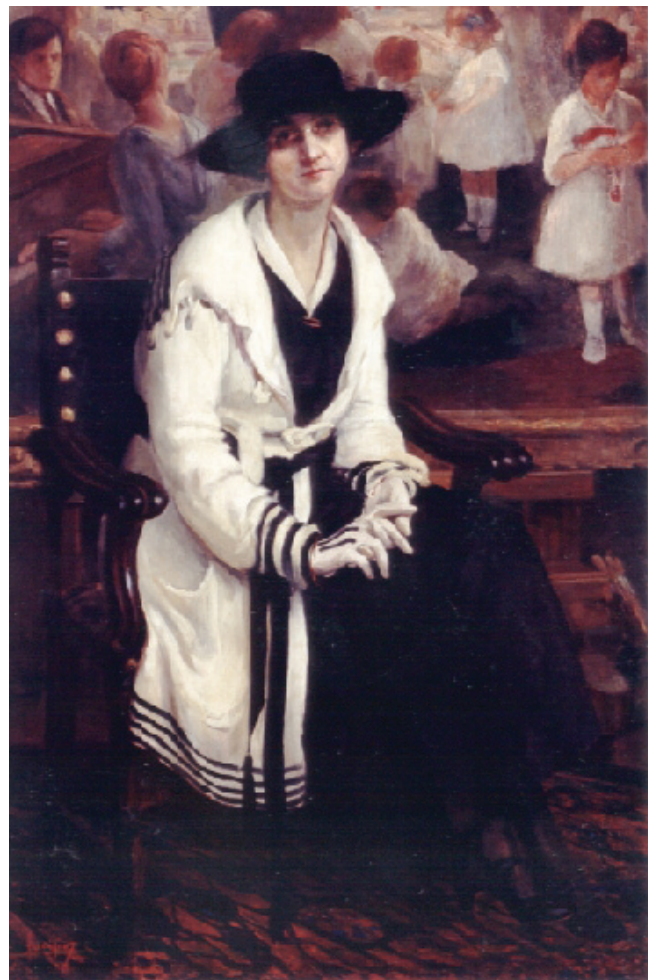

Retrato de Georgina por Lucilio de Albuquerque, 1920.

Disponível em https://pt.wikipedia.org/wiki/ Ficheiro:Luc\%C3\%ADlio_de_Albuquerque_-Retrato_de_Georgina,_1920.jpg 


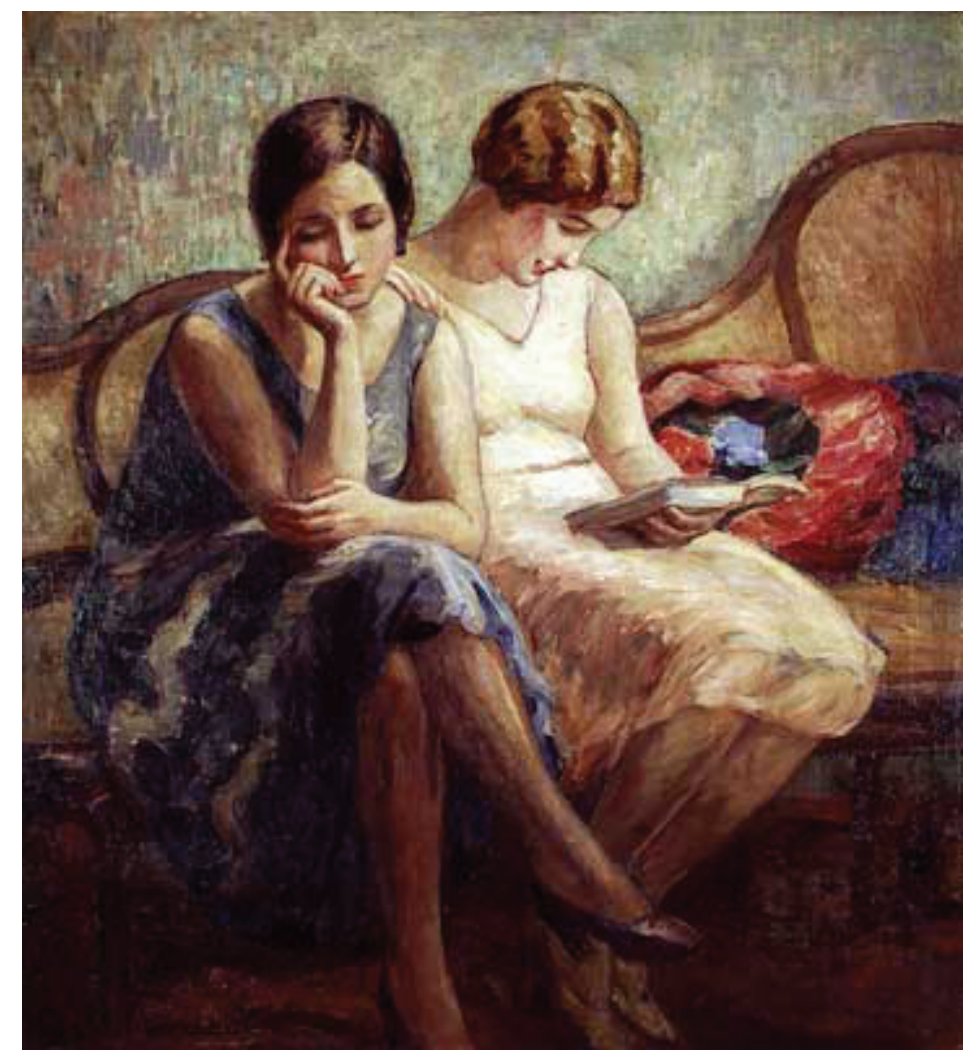

Meninas, de Georgina de Albuquerque. Disponível em http://www.elfikurten.com.br/2013/06/ georgina-de-albuquerque-o.html

Para tornar nossas artistas mulheres conhecidas faltam exposições antológicas dos melhores momentos de suas obras. Não estou falando de retrospectivas, que em geral feitas por historiadores diacrônicos, são um perigo para os/as artistas. Nas últimas retrospectivas que vi no Brasil os organizadores, no afã de mostrar o desenvolvimento, acabam por mostrar as fraquezas do artista.

Além disto a curadoria modernista virou clichê desenvolvimentista nas retrospectivas, com o esforço dos curadores em mostrarem que evolução artística é chegar à abstração, ao conceitualismo, à instalação ou ao objeto, apesar do artista ter começado figurativo.

Exposições antológicas escapam mais facilmente do perigo das interpretações únicas e da hegemonia das grandes narrativas na interpretação dos fatos históricos.

Na retrospectiva é oferecido um percurso traçado por outrem, um passeio de carro por uma rota que se impõe ao motorista e que ele testemunha visualmente em sequência. Já as exposições antológicas são como viagens de metrô. 
Cada obra é uma estação. Como não nos é dado ver o que está lá fora, as ruas, as pessoas, as árvores e as praças por cima do subterrâneo, o percurso entre as estações para reestabelecermos continuidade e sentido vai sendo preenchido pela imaginação visual e contextual do observador.

Hoje nas sombras, a imaginaria de mulheres artistas do pré-modernismo, nos intervalos da aparência retratada, atiça nossa reflexão acerca dos conflitos emocionais, intelectuais e sociais que estruturaram suas carreiras e demonstra o quanto a Arte esta interligada com a vida. E o reembricamento de Arte e Vida é uma das características da Pós-modernidade.

Há anos venho tentando fazer uma exposição de Maria Pardos.

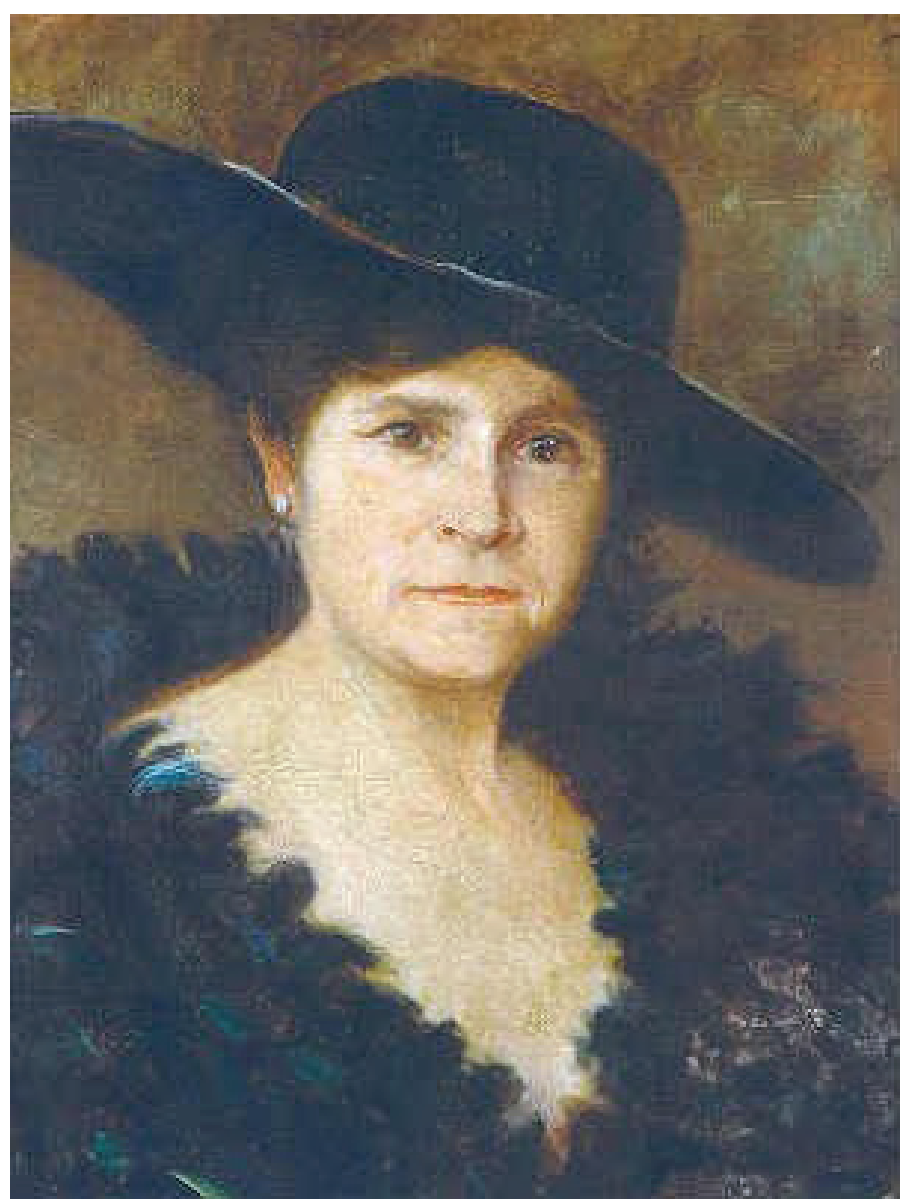

Maria Pardos, Autorretrato, c. 1918. Juiz de Fora,

Pinacoteca do Museu Mariano Procópio.

Descobri Maria Pardos em uma visita que fiz com Valéria e Ricardo, dois jovens e talentosos professores de Arte da UFJF ao Museu Mariano Procópio em 
Juiz de Fora, muitos anos atrás, Esse é talvez um dos cinco mais importantes $\mathrm{Mu}$ seus Históricos do Brasil. Além de excelente coleção de fotos de Nadar, da roupa com a qual Pedro II foi sagrado Imperador, de magníficos objetos e do mobiliário do Paço de São Cristóvão, um expressivo acervo de arte brasileira é abrigado por esse Museu que merece melhor trato e melhor conservação por parte dos poderes públicos. Os livros As barbas do Imperador de Lilia Schwarcz e o O Corpo do Herói de Maria Alice Milliet de Oliveira muito se basearam no acervo deste Museu.

Os museólogos, curadores, restauradores e mesmo o fotografo do Museu são de um empenho, competência e dedicação admiráveis. Quando o visitei faltava verba, por exemplo, para restaurar muitas das pinturas de Maria Pardos Foram todas restauradas recentemente.

O lado colecionista de Maria Pardos foi especialmente inteligente. Criou uma ala de pintores do século XIX no Museu, antes dela dedicado mais a História. As obras dos pintores brasileiros do acervo compradas com a intervenção de Maria Pardos são principalmente de seus ex-professores da Escola Nacional de Belas Artes. Graças ao fato de que Maria Pardos e o marido Alfredo Lage eram donos do Museu Mariano Procópio, somente doado à cidade depois da morte de Maria, podemos hoje contemplar sua obra, coisa que não aconteceu com uma outra artista esquecida, Silvia Meyer professora não só da ENBA mas do Instituto de Arte da Universidade do Distrito Federal criado por Anísio Teixeira (1935 a 1939).

Retrato de Sylvia Meyer,

Arthur Timótheo da Costa, 1912. Acervo SPHAN - Pró Memória / Museu Nacional de Belas Artes (Rio de Janeiro RJ). In: ENCICLOPÉDIA Itaú Cultural de Arte e Cultura Brasileiras. São Paulo: Itaú Cultural, 2020. Disponível em: <http://enciclopedia.itaucultural.org.br/obra23021/ retrato-de-silvia-meyer>. Acesso em: 09 de Mar. 2020. Verbete da Enciclopédia.

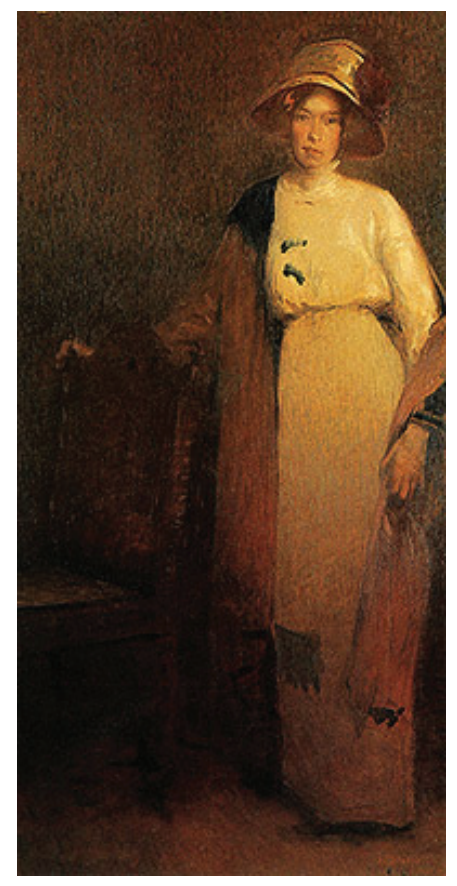

ISBN: 978-85-7979-060-7 
Sobre Sylvia Meyer estou em processo de pesquisa, conheci há uns 10 anos atrás uma neta da artista que me assegurou que tinha várias coisas da avó e fiquei de procura-la, a moça era jovem, bem mais jovem do que eu, e fui adiando essa entrevista que teria que fazem em Brasília ou Goiânia. Infelizmente ela morreu antes que eu conversasse com ela. Há muito pouca coisa sobre Sylvia Meyer. Com a ajuda da minha assistente Beatriz Correa encontrei esta carta de Gonzaga Duque apresentando-a a Eliseu Visconti. Incluo a carta pois o elogio feito a ela revela a posição da mulher nas artes naquela época. Para se elogiar uma mulher nas Artes Visuais era necessário primeiro reconhecer a inferioridade estética das mulheres. A fotografia subsequente ao texto da carta comprova que Eliseu Visconti a aceitou como aluna.

Em 27 de Fevereiro de 1910

Meu bom amigo e illustre professor Visconti

Honra-me e alegra-me o traçar destas linhas, porque ellas, sobre serem dirigidas a tão grande artista e bom amigo, vão apresentar-lhe Mlle. Sylvia Meyer, filha do meu amigo, o caritativo e illustre dr. Filippe Meyer. Mlle. Sylvia me parece um raro temperamento de artista e disso me convenço á vista dos seus progressos em um anno de estudos com o professor Amoêdo. Mas, Mlle. Sylvia, tem o idéal mais vasto do que as habilidosas do seu sexo, deseja completar os seus estudos e o mérito do meu caro Visconti fascina a sua alma de jovem e de apaixonada pela Arte. Ella pretende entrar para a aula do meu amigo, na Escola Nacional de Bellas Artes, em que conta ter grande aproveitamento. Só isso provaria a inclinação irresistível de Mlle. Sylvia para a pintura. Aqui a trago com estas linhas para que o meu illustre amigo se digne acolhê-la e explicar lhe as condições dessa matricula.

E por essa gentileza sou, como sempre,

Agradecido amigo e admor Gonzaga Duque

PS. Não o fui procurar, conforme prometti, por motivos independentes da minha vontade. Explicar-lh'os-ei depois. Honre me comprimentando Mme Luiza, e beijando a Yvonne.

Sempre grato, muito amigo e admor

GD48

48 Carta de Gonzaga Duque a Eliseu Visconti, apresentando Sylvia Meyer - 27 de fevereiro de 1910, disponível no Projeto Eliseu Visconti. Fonte: https://eliseuvisconti.com.br/documento/cr1910/ 


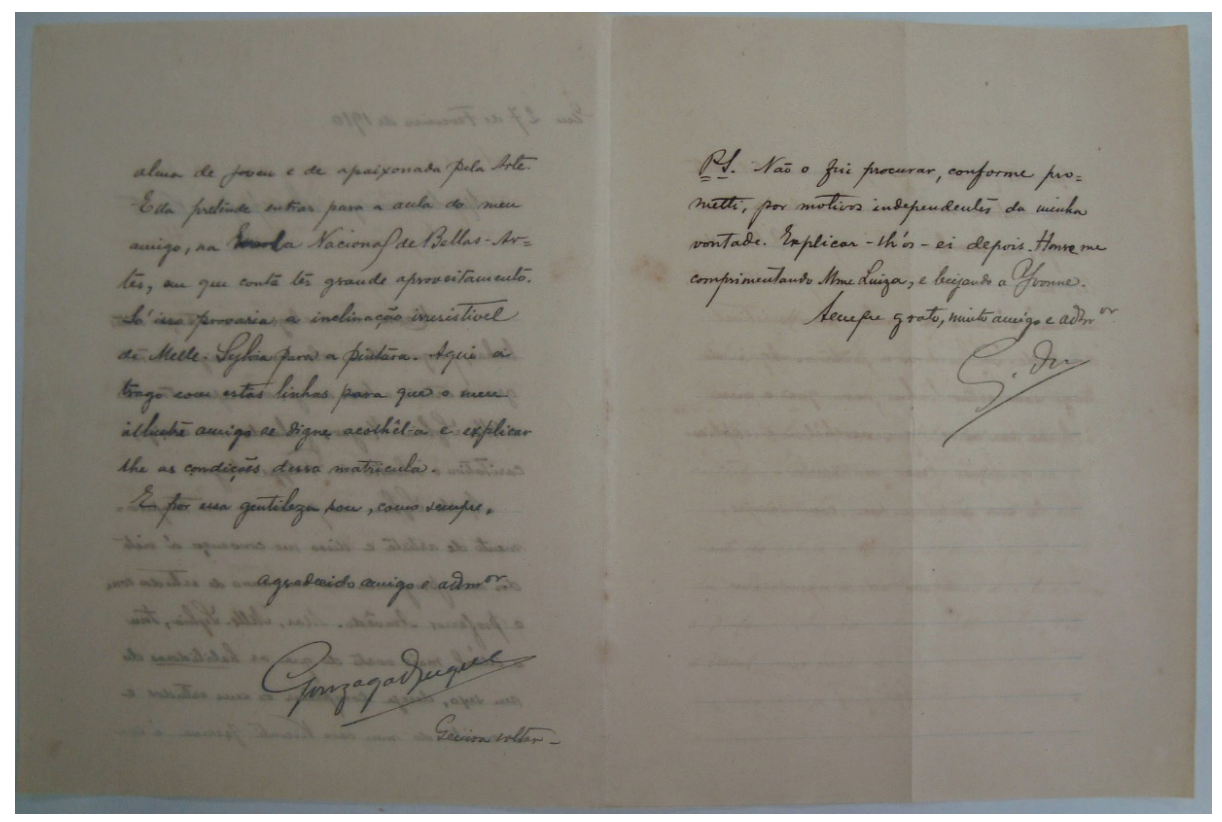

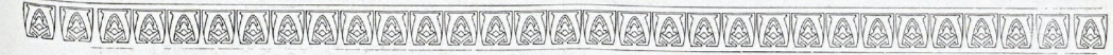

Fon-Fon! na Academia de Bellas Artes

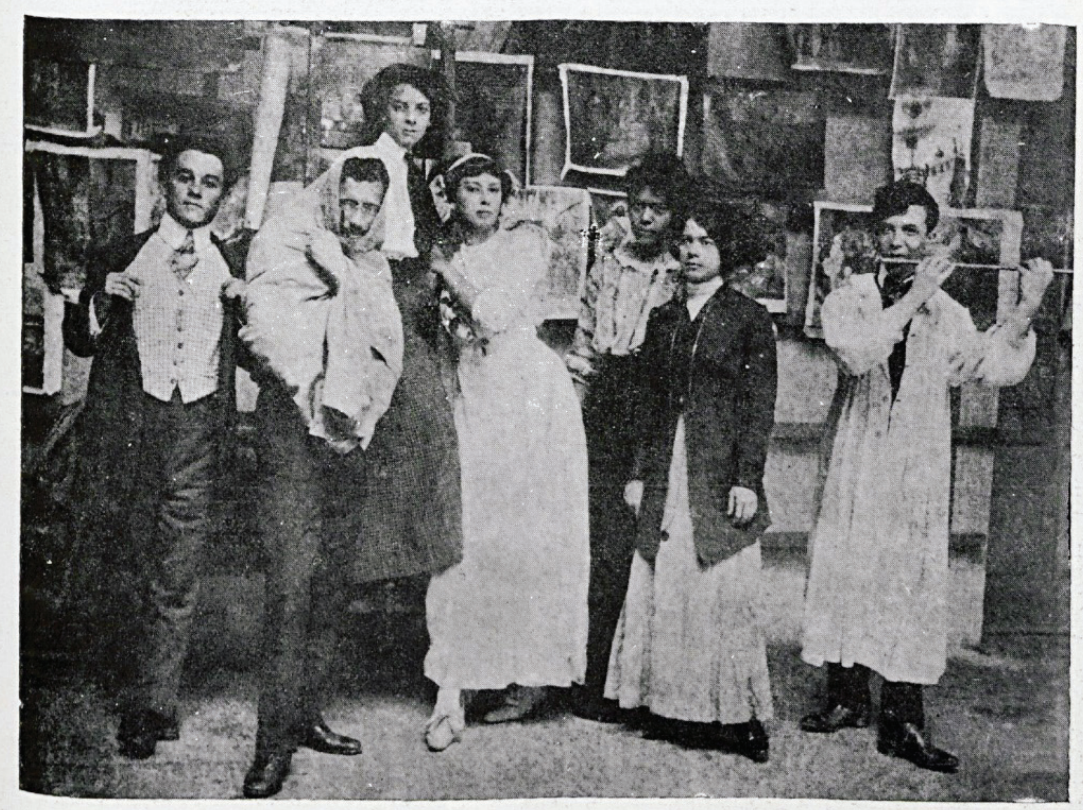

Grupo de discipulos do professor Elyseo Visconti (da esquerda para a direita) Galdino Bicho, Marques Junior, Isolina Machado, Silvia Meyer, Adelaide Gonçalves, Fedora
Rego Monteiro e H. Cavallero. 


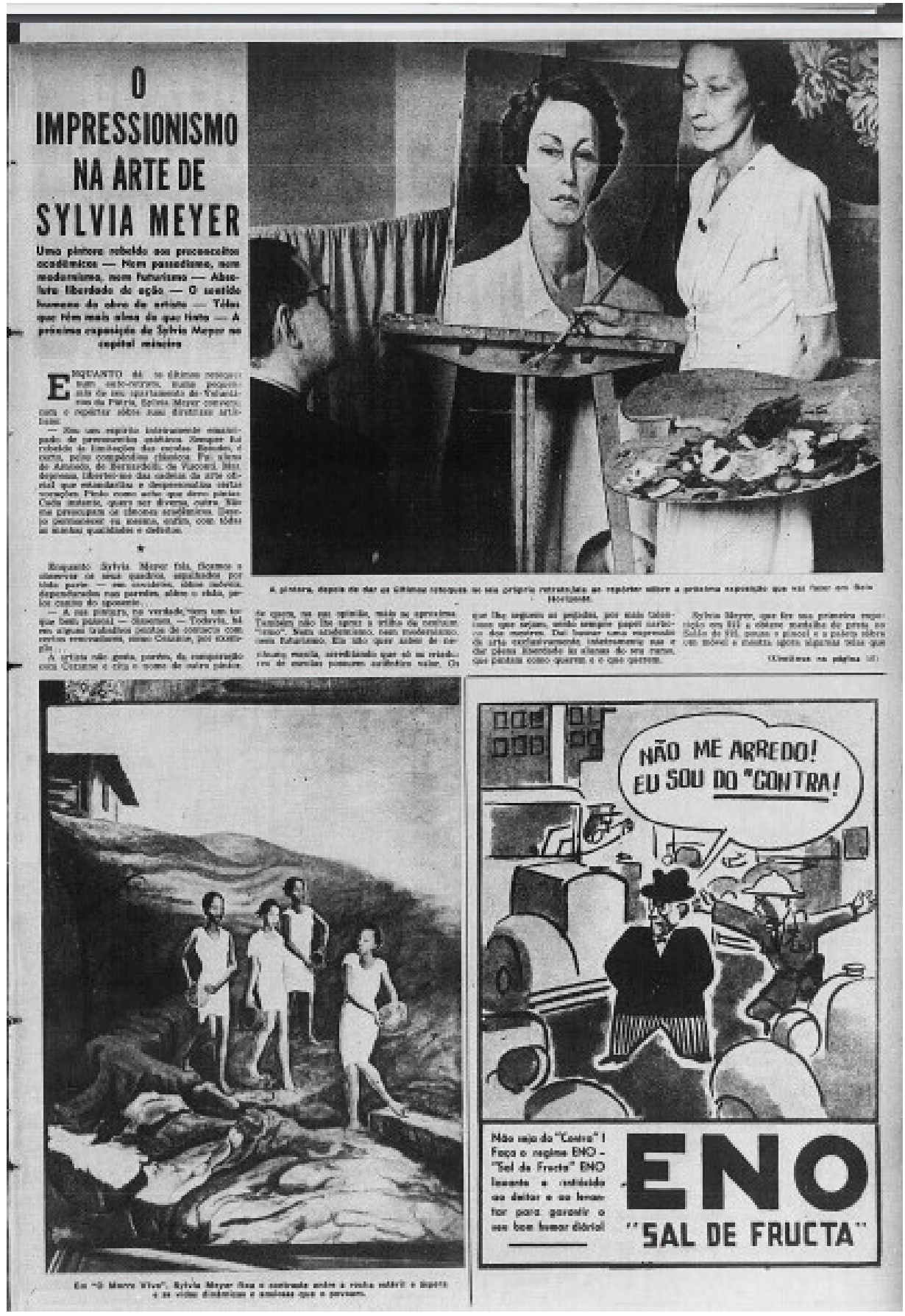

Jornal A Noite llustrada, agosto de 1946.

Fonte: http://memoria.bn.br/pdf/120588/per120588_1946_00911.pdf 


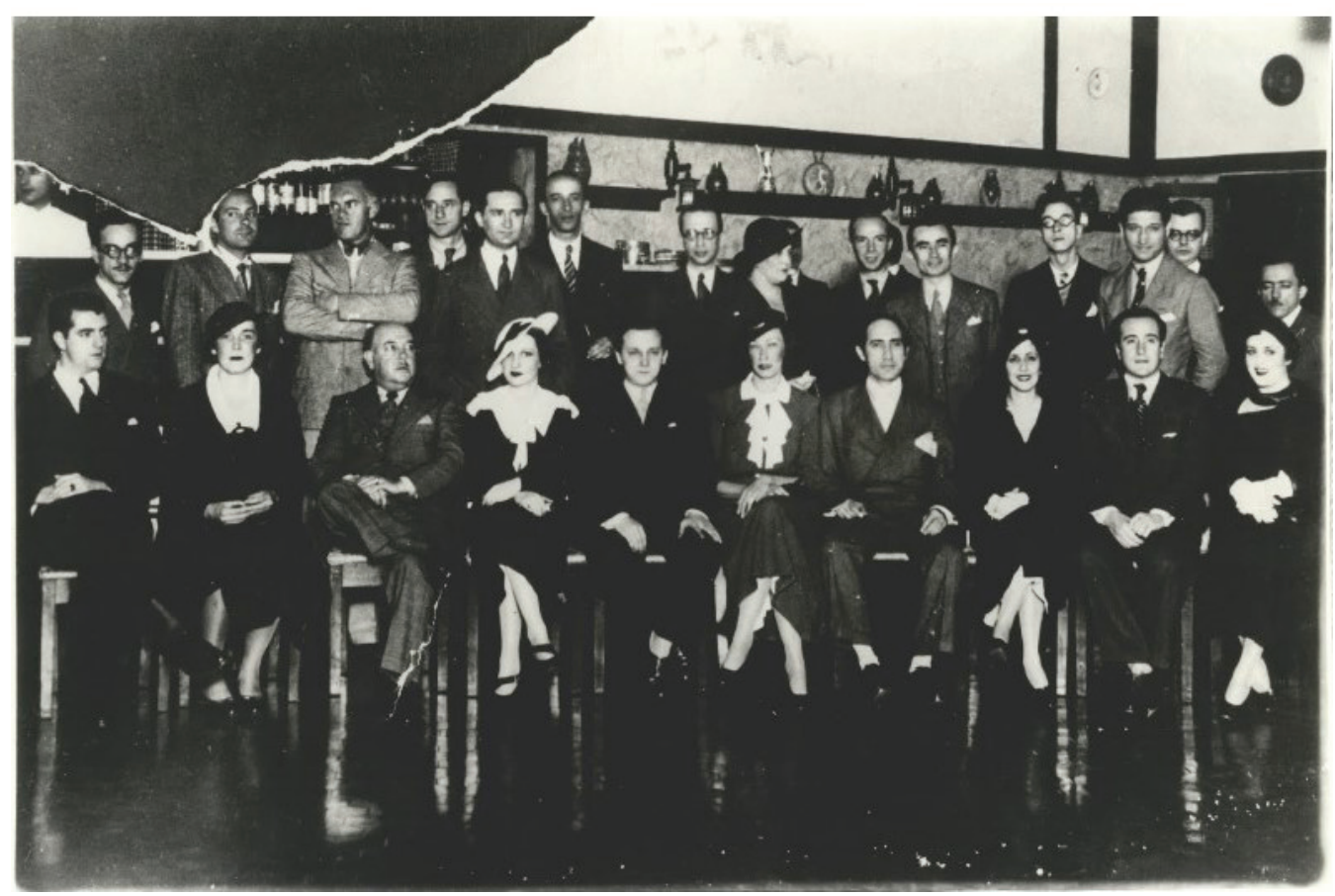

Grupo reunido no banquete em homenagem a Portinari, pelo sucesso de sua exposição no Palace Hotel.1929. Entre eles: Alfonso Reyes, Silvia Meyer, Celso Antônio, Hugo Adami, Guignard, Lelio Landucci, Antonio Bento, Murilo Mendes, Manuel Bandeira, Dante Milano, José Jobim, Alcântara Machado. Acervo do Projeto Portinari.

Disponível em: https://artsandculture.google.com/asset/homenagem-a-portinari/sgGKgg_u8x_ CLA?hl=pt-BR

A conquista da igualdade de gênero nas Artes Visuais começou no Brasil com os modernistas pós-Semana de Arte Moderna de 1922. Eles comungavam ideias anticolonialistas, que permitiram refletir sobre a igualdade de gênero, raça e códigos culturais. A partir de tais ideias foi possível reconhecer duas mulheres como as artistas mais importantes do modernismo brasileiro: Tarsila do Amaral e Anita Malfatti. Antes do advento do modernismo, algumas artistas haviam tido importância temporária, sendo, porém, invisibilizadas e excluídas da história da arte. Aliás continuam sendo excluídas. Ainda não houve uma revisão da produção artística das mulheres no passado brasileiro como já foi feito nos Estados Unidos. A prova é que o curador do segmento sobre o século XIX da Mostra do Redescobrimento, comemorativa da "descoberta" do Brasil por Portugal apresentada em 2000 no Parque do Ibirapuera em São Paulo, obediente a uma história da Arte etnocêntrica e excludente, não apresentou nenhuma obra de artista mulher, 
quando não precisava se aprofundar muito em pesquisas para descobrir não só Maria Pardos como Sylvia Meyer e Georgina de Albuquerque meus focos de interesse porém mais umas 200 artistas mulheres listadas em um livro esgotado há cinquenta anos de Theodoro Braga, que biografou democraticamente os pintores e as pintoras do Brasil na primeira metade do século XX. Portanto, as ideias modernistas por si só certamente não foram suficientes para manter a visibilidade de Amaral e Malfatti pois nos anos 40/50 elas já começavam a ser injustamente criticadas e invisibilizadas. Também teriam sido esquecidas, não fosse por duas outras mulheres, críticas de arte, que escreveram livros importantes sobre essas artistas. ${ }^{49}$ No Brasil, a celebrada igualdade é descartada pela falta de memória da produção de mulheres. Um exemplo dessa afirmação envolve dois protagonistas ativos no início do abstracionismo no Brasil das décadas de 1950 e 60, Samson Flexor e Yolanda Mohaly. Foi publicado um livro sobre Flexor, cujo trabalho foi comemorado por seus discípulos. Mohaly, entretanto, embora seja considerada melhor artista do que ele pelos vinte críticos e artistas que entrevistei informalmente, está sendo esquecida. Quando, para marcar os 10 anos de sua morte, pretendi organizar uma larga retrospectiva de sua obra só encontrei apoio em ex-amigos e em um ex-aluno. Ela que fora várias vezes premiada nas Bienais e São Paulo e que ensinara a tantos artistas hoje famosos, teve a homenagem restrita a uma exposição das obras que doara ao Museu de Arte Contemporânea, o qual eu dirigia na época.

Amaral, de influência marcadamente europeia, e Malfatti, sob grande influência norte-americana, estiveram em contato com sociedades mais abertas à participação feminina. Essa influência sem dúvida contribuiu para seu nível de confiança, mas não foi suficiente para garantir um processo continuado de construção estética revolucionária. Malfatti, na verdade, foi duramente criticada e quase destruída pelo poderoso escritor Monteiro Lobato que, em 1917, escreveu um artigo atacando-a, intitulado 'Paranoia ou Mistificação?' Penso que ele e seus contemporâneos, embora concentrassem sua crítica no estilo modernista de Malfatti, estavam certamente escandalizados pela liberdade daquela jovem em representar nus masculinos com gestos femininos, uma representação de sexualidade ambígua. A sexualidade, não o estilo, era o motivo da crítica agressiva, machista e destrutiva contra a arte de Malfatti. É curioso notar que essas duas mulheres, que fizeram a mudança dos paradigmas estéticos na arte brasileira dos anos 1920, no final de suas vidas pintavam o que a sociedade espera de mulheres: paisagens sem graça e temas religiosos. As normas sociais insidiosas prevaleceram sobre seu comportamento artístico.

49 Refiro-me a Aracy Amaral e Marta Rosseti que, respectivamente, escreveram sobre Tarsila do Amaral e Anita Malfatti. 
No Brasil, o desafio do modernismo contra as definições tradicionais das belas artes ajudaram mulheres a trazer visibilidade para sua arte. Por exemplo, a gravura era tradicionalmente considerada uma arte de segunda categoria e, por conseguinte, um meio tipicamente feminino, embora os grandes mestres fossem homens. Quando os conceitos artísticos mudaram e o status da gravura ascendeu, muitas mulheres já eram conhecidas como gravuristas de talento e, consequentemente, o status delas, como artistas, se consolidou. Por outro lado, o desafio à primazia da pintura e à supremacia da arte como bem de consumo abriu o campo para meios alternativos, tais como instalações - de valor mercadológico reduzido - que vinham sendo um campo de realização bem sucedida das artistas mulheres no Brasil. Basicamente, desde que não haja dinheiro envolvido, as mulheres podem fazer parte do cenário; havendo envolvimento financeiro, porém, a igualdade logo é desestabilizada. Maria Martins, por exemplo, foi uma escultora de alta qualidade, muito premiada nos anos 1950, entretanto foi apagada pela História por muitos anos. Hoje é conhecida porque especialistas europeus descobriram seu envolvimento amoroso com Marcel Duchamp e consequentemente críticos começaram a reavalia-la.

Os anos 80 e 90 do século XX foram especialmente desclassificantes do feminismo no sistema das Artes no Brasil, enquanto nos Estados Unidos os anos 90 foram de consolidação do feminismo .

Grande parte das artistas mulheres que conseguiam visibilidade considerável, no Brasil, se recusam a serem vistas como artistas mulheres e, portanto, se recusam a reconhecer as diferenças de gênero. Em 1989, por exemplo, Josely Carvalho, artista brasileira residente em Nova York, e Sabra Moore organizaram uma exposição intitulada Conexus: Artistas Mulheres, Brasileiras e Norte-Americanas, em Diálogo. Foi bastante difícil obter a participação de artistas brasileiras de visibilidade semelhante a das artistas americanas que participaram da mostra. Os argumentos incluíam "Não quero vínculos com exposições só de mulheres, sou tão importante quanto um homem, não quero ser vista separadamente" e 'Para expor, não preciso apelar para gênero; esse é o caminho das artistas sem qualidade". Ficou claro que, segundo pensavam, perderiam status caso fossem vistas como artistas mulheres.

Críticos/as de arte reforçaram por muitos anos esse tipo de metapreconceito. Recusavam-se a confrontar categorizações de gênero, temendo serem vistos como críticos de segunda classe. Quando o Museu de Arte Moderna de Nova York me convidou para falar durante uma exposição de arte latino-americana, me orgulhei por ser aquele um dos museus mais importantes do mundo. Mas porque o convite veio para falar em uma mesa redonda sobre a arte das mulheres, fui bastante desestimulada. Um dos comentários, feito por uma crítica e historiadora da 
arte, foi especialmente inesquecível: "Nenhum crítico de arte importante aceitaria falar numa mesa-redonda sobre esse assunto". O engraçado é que alguns norte-americanos importantes aceitaram.

Outro exemplo de preconceito ocorreu quando Carvalho, Moore e eu tentamos trazer a exposição "Conexus" para o Brasil. Enfrentamos a dificuldade de patrocínio. No Brasil, empresas privadas evitavam patrocinar qualquer forma de arte visual ligada à diferença: arte das mulheres, arte afro, arte indígena e assim por diante. Embora Carvalho e Moore tenham finalmente trazido a exposição para o Museu de Arte Contemporânea, a imprensa deu pouquíssimo destaque.

Suspeitava-se que uma artista que aceite ser identificada como mulher seja necessariamente medíocre. Trabalhos de artistas americanas de renome, como Ida Applebroog, Faith Ringgold, Nancy Spero e May Stevens, Louise Bourgeois e de latino-americanas em Nova York, como Liliana Poter e Catalina Parra, foram expostos pela primeira vez no Brasil na exposição Conexus mas passaram quase desapercebidos por terem sido apresentados como arte de mulheres. Posteriormente, entretanto, Spero, Porter e Bourgeois expuseram com sucesso no Brasil, mas o fizeram em mostras sem classificação de gênero. Sem essa referência explícita, puderam ser vistas e apreciadas. Um olhar superficial dirá que artistas mulheres são numerosas e têm visibilidade, e que aparentemente recebem tratamento semelhante aos artistas homens. Entretanto, se cruzarem os caminhos das diferenças sociais, tais como gênero, raça ou classe social, essa igualdade desaparece. Por exemplo, em 1992, pesquisando as dez galerias de arte mais importantes (em termos financeiros) de São Paulo, algumas no mercado por quase vinte anos, descobri que nunca haviam exposto uma artista-mulher negra, embora algumas já tivessem exposto artistas-homens negros. É surpreendente que num país miscigenado, hipocritamente divulgado como paraíso racial, problemas de gênero e raça se ocultem por trás de preconceitos baseados em classificações sociais.

Até pouco tempo, as mulheres escolarizadas das classes médias e abastadas, no Brasil, tinham pouca dificuldade de conseguir empregos de pouca importância, porque não havia homens egressos de universidades em número suficiente para preencher as posições disponíveis. Mesmo hoje, apesar do crescente número de universidades nos últimos vinte anos e maior frequência de mulheres que de homens nestas universidades $95 \%$ da população tem desconfiança no trabalho das mulheres. Isto saiu veiculado por jornais e televisões entre os dias 1 a 6 de março, as vésperas do dia da Mulher de 2020. Da para ver que as mulheres no Brasil são machistas Graças às ideias positivistas de Auguste Comte, que influenciaram o Brasil, desde o século XIX, as mulheres têm recebido educação formal, mas o machismo é mais poderoso

O percentual de estudantes do sexo feminino é alto, principalmente nas 
ciências humanas; e nas artes, elas constituem $82 \%$ do corpo discente. Mas em geral, o percentual de homens bem sucedidos é maior do que o de mulheres. Sucesso não depende só de competência. Essa é provavelmente uma das razões porque obras de artistas homens são maioria em museus, exposições, galerias.

Nos anos recentes, os efeitos da recessão e do desemprego começaram a afetar a facilidade com que mulheres escolarizadas conseguiam garantir boas posições profissionais. Na competição profissional, elas sempre perdem para os homens, não importa se estes são brancos ou negros, heteros ou homossexuais. A revista VEJA, de grande circulação nacional, provou esse fato através de entrevistas com homossexuais no mês de junho de 1993. Todos os entrevistados concordaram que as mulheres são mais discriminadas do que os homossexuais. Um incidente na administração da cidade de São Paulo, em 1992, ajudou a confirmar esse achado. A diretora de um museu paulistano, posição essa ocupada por várias mulheres no passado, foi demitida por um secretário de cultura sob a desculpa de que o secretário achava que mulheres não deviam coordenar museus devido à natureza complexa da função. Em consequência, somente homens dirigiram os museus sob a responsabilidade do secretário de cultura de São Paulo de 1992 a 1995.

Não quero passar uma impressão pessimista de meu país, porque sou otimista por natureza.

Aplicado às artistas brasileiras, o comentário de Virgínia Woolf sobre escritoras na História é bastante apropriado; ela disse que mulheres querendo passar por homens em sua escrita era muito comum, mas se a História tivesse dado um lugar às mulheres que queriam escrever como mulheres, a História teria sido diferente. Parafraseando Simone de Beauvoir e Eva Hesse, eu diria que para esquecer que se é mulher, antes de mais nada é necessário ter plena certeza de que se é uma mulher e lutar pela conscientização de todas as mulheres para que pelo menos não votem em político que as querem reduzir a vassalas do machismo que praticam.

\section{Bibliografia}

A Mensageira - revista literária dedicada à mulher brasileira (1897-1900); São Paulo: Imprensa Oficial do Estado, IMESP, 1987 (edição fac-similar). Vol 1 e Vol 2.

BARBOSA, Ana Mae. "Art in Brasil: several minorities". In: FARRIS-DUFRENE, Phoebe. Voices of Color: Art and Society in the Americas; New Jersey, Humanities Press, 1997.pag 65 a 71.

. "Artistas de sucesso esquecidas pela História: uma ques- 
tão de política cultural". In: La igualdad não es una utopia. Anais do Congreso Internacional e Interdisciplinar Mundos de Mujeres. Madri: Universidade Complutense e Thomson Aranzadi, 2008, pag 29 a 36.

; AMARAL, Vitoria (Orgs.). Mulheres não devem ficar em silencio: Arte, Design e Educação. São Paulo, Editora Cortez: 2019.

BROUDE, Norma; GARRARD, Mary D. Feminism and Art History: questioning the litany, New York, Icon Editions/ Happer \& Row, Publishers, 1982.

CHICAGO, Judy. The Dinner Party NY: The Doubleday Anchor Book, 1996.

COLLINS, Georgia; SANDELL, Renee. Women, Art and Education. Reston, Virginia: National Art Education Association, 1984.

ETIENNE, Mona; LEACOCK, Eleanor (org). Women and Colonization: Anthropological Perspectives; New York, Praeger, 1980.

FANTHAM, Elaine; PEET FOLEY, Helene; KAMPEN, Natalie Boymel; POMEROY. Sarah B.; SHAPIRO, H. ${ }^{a}$. Women in the Classical Word; New York and Osford, Osford Univerty Press, 1994.

FARRIS-DUFRENE, Phoebe. Voices of Color: Art and Society in the Americas; New Jersey, Humanities Press, 1997.

FRUEH, Joanna and Cassandra L. Langer, Arlene Raven. New Feminist Criticism: art. Identity, action, New York, Icon Editons, $1^{\text {a }}$ ed. 1991, 1994.

FREIRE, Paulo. Pedagogia do Oprimido. Rio de Janeiro, Ed. Paz e Terra, 2000.

GREER, Germaine. The Obstacle Race; London, Book Club Associetes, 1980.

LEITE, Míriam Moreira (org.). A Condição Feminina no Rio de Janeiro, Século XIX: antologia de viajantes estrangeiros; São Paulo/Brasília: Editora Hucitec/ EDUSP/ INL, Fundação nacional Pró-Memória, 1984 (Estudos Históricos;4).

LIPPARD, Lucy R. Get the Message? A decade of art for social change; New York, Dutton, Inc., 1984.

York, The New Press, 1995.

MUNRO, Eleanor. Originals: American Women Artists. New York, Simon\& Schuster, 1979. 
OLIVEIRA, Miriam Andrea de. Abigail de Andrade: Artista Plástica do Rio de Janeiro no século XIX. Dissertação de Mestrado UFRJ-EBA,1993.

PARKER, Rozsika; POLLOCK, Griselda. Old Mistresses: women, art and ideology; London, Routledge\& Kegan Paul, 1981.

SIMIONI, Ana Paula. Profissão Artista. São Paulo: EDUSP, 2004.

BARROS, Roberta. Elogio ao toque: ou como falar de arte feminista à brasileira. Rio: Relacionarte, 2016.

SPALDING, Frances. Garden Ceremony. In: TLS,19 de Fevereiro de 1999, pag 19. ZACCARA, Madalena (Org.). De sinhá prendada a artista visual: os caminhos da mulher artista em Pernambuco. Recife: Ed. Do Organizador, 2017. 